\title{
Role of Exercise-Induced Calmodulin Protein Kinase (CaMK)II Activation in the Regulation of Omega-6 Fatty Acids and Lipid Metabolism Genes in Rat Skeletal Muscle
}

\author{
J. S. JOSEPH ${ }^{2}$, A. O. AYELESO ${ }^{1}$, E. MUKWEVHO ${ }^{1}$ \\ ${ }^{1}$ Department of Biological Sciences, North-West University, Mafikeng Campus, Mmabatho, South \\ Africa, ${ }^{2}$ Department of Biochemistry, University of Johannesburg, South Africa
}

Received October 12, 2016

Accepted May 11, 2017

On-line September 22, 2017

\begin{abstract}
Summary
Activation of calmodulin dependent protein kinase (CaMK)II by exercise is beneficial in controlling membrane lipids associated with type 2 diabetes and obesity. Regulation of lipid metabolism is crucial in the improvement of type 2 diabetes and obesity associated symptoms. The role of CaMKII in membrane associated lipid metabolism was the focus of this study. Five to six weeks old male Wistar rats were used in this study. GCXGC-TOFMS technique was used to determine the levels of polyunsaturated fatty acids (linoleic acid, arachidonic acid and 11,14-eicosadienoic acid). Carnitine palmitoyltransferase (Cpt-1) and acetyl-CoA carboxylase (AcC-1) genes expression were assessed using quantitative real time PCR (qPCR). From the results, CaMKII activation by exercise increased the levels of arachidonic acid and 11,14-eicosadienoic acid while a decrease in the level of linolenic acid was observed in the skeletal muscle. The results indicated that exercise-induced CaMKII activation increased CPT-1 expression and decreased ACC-1 expression in rat skeletal muscle. All the observed increases with activation of CaMKII by exercise were aborted when KN93, an inhibitor of CaMKII was injected in exercising rats. This study demonstrated that CaMKII activation by exercise regulated lipid metabolism. This study suggests that CaMKII can be a vital target of therapeutic approach in the management of diseases such as type 2 diabetes and obesity that have increased to epidemic proportions recently.
\end{abstract}

\section{Key words}

CaMKII • Lipid metabolism • Linoleic acid • Arachidonic acid • Eicosadienoic acid

\section{Corresponding author}

E. Mukwevho, Department of Biological Sciences, North-West University, Mafikeng Campus, Mmabatho, 2735, South Africa. E-mail: emmanuel.mukwevho@nwu.ac.za

\section{Introduction}

Excess and accumulation of various lipid species in the cell has been associated with the pathogenesis of metabolic disorders such as type 2 diabetes and obesity (Koves et al. 2005, Bruce et al. 2006, Kinfe et al. 2014). Thus, lipids regulation in the cell is crucial in the management of these metabolic disorders caused due to excess of lipid species. Obesity is a very severe disease that may lead to the development of type 2 diabetes and insulin resistance (Gao et al. 2004, Kinfe et al. 2014). The dominant and most promising approach to mitigate and deter type 2 diabetes is lifestyle intervention, e.g. weight reduction, decreased total and saturated fat consumption, and increased physical activity (Knowler et al. 2002, McAuley et al. 2002). Regular exercise increases oxidation of fatty acids and glucose transport in skeletal muscle (Ren et al. 1996, Holloszy and Booth 1976, Mukwevho and Joseph 2014). This can delay the onset or prevent and even reverse type 2 diabetes. Exercise mitigate the symptoms of diabetes (excess lipids and glucose) through 'in part' by activation of calmodulin dependent protein kinase (CaMK)II (Ojuka et al. 2003, Mukwevho et al. 2008, Mukwevho and Joseph 2014). This results in increased mitochondrial oxidative capacity and improved glucose uptake (Chin 2005, Bruce et al. 
2006). CaMKII is a serine/threonine specific protein kinase and it activated when cytosolic $\mathrm{Ca}^{2+}$ levels rise. CaMKII is different from other CaM kinases owing to its ability to autophosphorylate at Thr286. Binding of $\mathrm{Ca}^{2+} / \mathrm{CaM}$ to $\mathrm{CaM}$ binding domain of CaMK activates enzymes by its structural arrangement in subunits that uncover Thr286 in autoinhibitory the domain and catalytic domain (Payne et al. 1988).

Abnormalities in the membrane composition of fatty-acids may be involved in the pathogenesis of diabetes and obesity (Borkman et al. 1993). Arachidonic acid (AA), a 20-carbon polyunsaturated fatty acid (PUFA), is a basic constituent of cell membranes (Meirer et al. 2014). Skeletal muscle is chiefly the active site of AA retention, amounting to about $10-20 \%$ of the phospholipid fatty acid content (Smith et al. 2011). Linolenic acid (LA), a major dietary PUFA is a metabolic precursor to AA, linked biochemically via two desaturases and an elongase (Rett and Whelan 2011). When other omega-6 (n-6) PUFA (including dietary AA) are absent, dietary LA is the sole contributor to tissue AA (Rett and Whelan 2011). Human adults have been reported to be capable of converting of LA (18:2 n-6) to AA (20:4 n-6) (Salem et al. 1999). Arachidonic acid is an essential regulator of cellular function through its actions on the physical properties of membranes either in its free form or as a substrate for eicosanoids (Phinney 1996). AA plays important roles in regulating lipid metabolism (Tian et al. 2014) and its high concentration in the muscle tissue has been reported to positively correlate with increased insulin sensitivity in skeletalmuscle phospholipids (Borkman et al. 1993).

The mitochondria plays significant role in lipid metabolism. Lipid metabolism is controlled by a set of mitochondrial enzymes that operate interchangeably. For example, carnitine palmitoyltransferase (CPT)-1 is a ratelimiting enzyme in mitochondrial lipid oxidation by regulating transport of long chain fatty acids across mitochondrial membrane. On the other hand, acetyl-CoA carboxylase (ACC)-1 is a mitochondrial enzyme that promotes lipid synthesis by providing malonyl CoA substrate for biosynthesis of fatty acids (Tong 2005). It is reported that down-regulation of ACC-1 and upregulation of CPT-1 may result in increased oxidative capacity of the mitochondria by reduction in lipid accumulation and obesity in adipocytes and myocytes (Kinfe et al. 2014). Although ACC-I is in extremely low levels in the skeletal muscle, it has been suggested to possibly compensate for a lack of ACC-2 (Olson et al.
2010). O'Neil et al. (2015) reported that phosphorylation of ACC-1 and ACC-2 is not required for maintaining endurance exercise capacity or whole-body rates of fatty acid oxidation during submaximal endurance exercise. Also, Wicks et al. (2014) reported that accumulation of lipids in the muscles did not lead insulin insensitivity in a near-complete knockdown of gene and activity of muscle-specific CPT-1. However, despite these contrary reports, studies have supported the involvement ACC and CPT-1 in lipid metabolism in muscles. For example, ACC expression in muscles has been linked to exercise or cellular stress which corroborates the link between ACC and fatty acid metabolism (Dean et al. 2000, Hardie and Pan 2002). It has also been supported that muscle-specific over-expression of CPT-1 enhances fatty acid oxidation (Bruce et al. 2009). The activation of CaMKII by exercise on the regulation of CPT-1 and ACC-1 is still yet to be determined. The aim of this study was to determine the role of exercised-induced CaMKII on the levels of polyunsaturated acids and regulation of lipid metabolism enzymes in skeletal muscles of experimental rats.

\section{Materials and Methods}

\section{Animal handling and exercise protocol}

Five to six weeks old male Wistar rats were used in this study. All animal procedures were approved by Animal ethics committee of the University of Witwatersrand, South Africa. Rats were fed with standard rat chow and water ad libitum. Room temperature was maintained at $21-24{ }^{\circ} \mathrm{C}$ with a $12 \mathrm{~h}$ light/dark cycle. Their welfare and weights were checked daily.

In this study, the total number of rats used was 18 rats. The rats were divided into three groups of 6 rats each, namely: control (non-exercise), exercise and exercise + KN93. KN93 (N-[2-[N-(4-Chlorocinnamyl)$\mathrm{N}$-methylaminomethyl]phenyl]-N-(2-hydroxyethyl)4-methoxybenzene sulfonamide phosphate salt) was dissolved in DMSO and used as CaMKII inhibitor. KN93 was given to the rats by intraperitoneal injection at a dose of $5 \mathrm{mg} / \mathrm{kg}$. Rats were exercised according to protocol described by Terada et al. (2001) and Smith et al. (2007). The swimming protocol used to exercise the rats is indicated by a flow diagram in Figure 1. From day 1 to day 4, rats were housed and familiarized to handling. Thereafter, from day 5 to day 8 , rats were familiarized to swimming protocol as follows: on day 5, rats were subjected to 2 bouts of $17 \mathrm{~min}$ swimming and $3 \mathrm{~min}$ rest 
in between bouts. From day 6 to day 8, rats were made to perform similar exercise protocol but the number of bouts increased by one bout per day. From days 9 to 14, rats were rested in their cages in order to ensure that familiarization protocol did not affect the experiment.

On day 15, control and exercise group received intraperitoneal injection of $5 \mathrm{mg} / \mathrm{kg}$ of DMSO and exercise + KN93 group received $5 \mathrm{mg} / \mathrm{kg}$ of KN93, $30 \mathrm{~min}$ prior to exercise. After injection, exercise and exercise + KN93 groups performed 5 bouts of 17 min of swimming with $3 \mathrm{~min}$ of rest in between bouts. This procedure was then repeated at a similar time for exercise and exercise + KN93 groups on days 16, 17, 18 and 19 . In addition, rats were fasted night before experiment. Control group remained caged for entire duration of the experiment and fasted at the same time as exercise group. Rats were then anesthetized $6 \mathrm{~h}$ post-exercise at day 19 by intraperitoneal injection of sodium pentobarbital $(50 \mathrm{mg} / \mathrm{kg})$. Muscles were dissected out for analysis, snap frozen in liquid nitrogen and stored at $-80{ }^{\circ} \mathrm{C}$ freezer in cryovial until required for use.

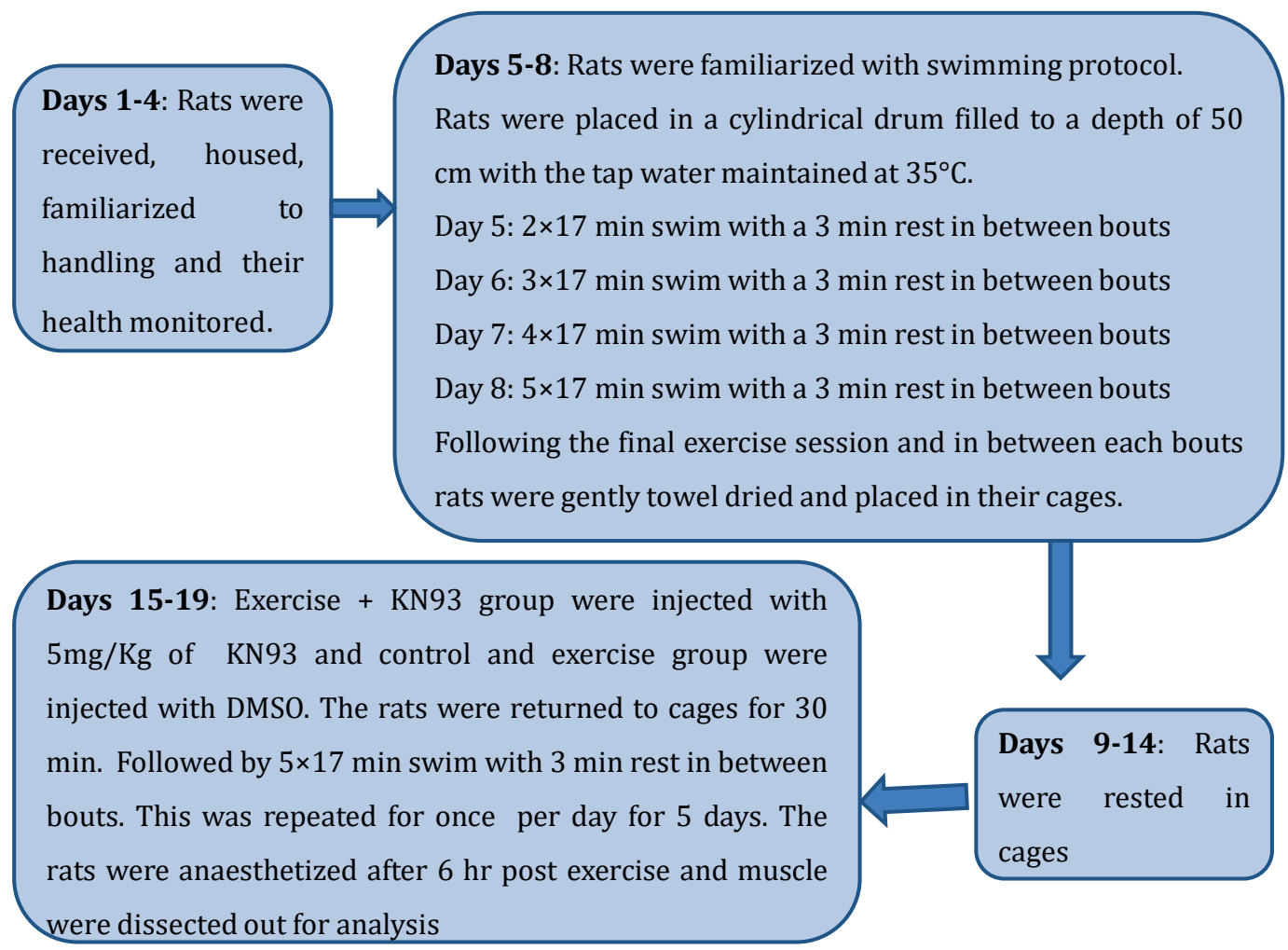

Fig. 1. Diagrammatic flow chart of the swimming protocol used to exercise the rats.

\section{Western blot}

Gastrocnemius muscle was homogenized with liquid nitrogen and transferred to $850 \mu$ l of RIPA buffer (1 M Tris $\mathrm{HCl}, 2.5 \mathrm{M} \mathrm{NaCl}, 0.5 \mathrm{mM}$ EDTA, $10 \%$ SDS, $0.1 \mathrm{M} \mathrm{Na}_{4} \mathrm{P}_{2} 0_{7}, 0.5 \mathrm{M} \mathrm{NaF}, 100 \mu \mathrm{M}$ okadaic acid, $2 \mathrm{M}$ $\mathrm{Na}_{3} \mathrm{VO}_{4}, 25 \times$ Roche complete protease inhibitor and $100 \%$ Triton X100). Thereafter, sample was sonicated for $3 \mathrm{~s}$ at $33 \%$ maximum sonicator intensity on ice, centrifuged at $3,600 \mathrm{rpm}$ for $5 \mathrm{~min}$ at $4{ }^{\circ} \mathrm{C}$. Resultant supernatant was collected and protein concentration measured by using Bradford assay method. Protein extract was then added into reducing sample buffer (0.5 M Tris $\mathrm{HCl} \mathrm{pH} 6.8,2 \%$ glycerol, $10 \% \mathrm{SDS}, \pm 5 \%$ mercaptol-ethanol and $0.01 \%$ bromophenol blue), heated at $95{ }^{\circ} \mathrm{C}$ for $5 \mathrm{~min}$ and proteins were separated by $7.5 \%$ gel by SDS PAGE. Proteins from SDS PAGE were then transferred to a PVDF (polyvinyldiene diflouride) membrane for $55 \mathrm{~mA}$ overnight at $4{ }^{\circ} \mathrm{C}$. Membrane was then blocked for $1 \mathrm{~h}$ at room temperature (RT) with $5 \%$ bovine serum albumin containing $1 \times$ Tris buffered saline, $0.1 \%$ Tween 20 (TBS-T) (20 mM Tris-base, $8 \%$ $\mathrm{NaCl}, 1 \mathrm{M} \mathrm{HCl}, 0.1 \%$ Tween 20). Thereafter, membrane was incubated with antibodies against CPT-1 (Sigma, Anti-Cpt-1 1:1000 dilution in TBST) and ACC-1 (Cell Signalling, Anti-ACC-1 1:1000 dilution in TBST) at $4{ }^{\circ} \mathrm{C}$ overnight. Thereafter, the membrane was washed 
for $3 \times 5 \mathrm{~min}$ in TBS-T and incubated with appropriate HRP conjugated secondary antibody (Anti-rabbit IgG antibody) for $1 \mathrm{~h}$ at RT. Membrane was then incubated for $5 \mathrm{~min}$ with enhanced chemiluminescence solution containing $1 \mathrm{ml}$ of peroxidase and $1 \mathrm{ml}$ substrate (Amersham, South Africa). Proteins were visualized under Chemi Doc system TM XRS system (Biorad) and analyzed by using image lab software. Protein expression was normalized with alpha tubulin.

\section{Fatty acid analysis ( $G C \times G C-T O F M S)$}

In order to assess AA and LA from the muscle in response to exercise, lipids were isolated from Gastrocnemius muscle using the modified method of Folch et al. (1957). One gram of ground muscle was homogenized with chloroform : methanol $(2: 1)$ to a final volume of 20 times the weight of sample ( $1 \mathrm{~g}$ in $20 \mathrm{ml}$ of solvent mixture). The sample was then vortexed and sonicated at $33 \%$ maximal speed for 30 min on ice. After sonication, the sample was kept at RT on an orbital shaker for $20 \mathrm{~min}$ and was then filtered and washed with $4 \mathrm{ml}$ of water. Thereafter, the sample was vortexed for few seconds, centrifuged at low speed $(2,000 \mathrm{rpm})$, and the upper phase was removed. The sample was then dried using a rotary evaporator at $62{ }^{\circ} \mathrm{C}$. The weight of the sample checked, dissolved in chloroform $(8 \mathrm{mg} / \mathrm{ml})$, and dried again using rotary evaporator. To identify the fatty acids methyl esters by GC-MS, derivatization was done by using $3 \mathrm{M}$ methanolic $\mathrm{HCl}$; this was added to sample at ratio $1: 2(\mathrm{v} / \mathrm{v})$. The samples were then heated at $60{ }^{\circ} \mathrm{C}$ for $1 \mathrm{~h}$ in a water bath. The derivatised product was then left to cool down at RT and $1 \mathrm{ml}$ of distilled water was added for phase separation. Lipophilic extractives were then recovered 2-times with $1 \mathrm{ml}$ of $\mathrm{n}$-hexane. Thereafter, the solvent was evaporated by using a rotary evaporator at $69^{\circ} \mathrm{C}$ and then re-dissolved in $300 \mu$ l of HPLC grade n-hexane for analysis (Ichihara et al. 1996). Before injection, the samples were filtered with $0.2 \mu \mathrm{m}$ PTFE syringe filter.

Fatty acid analysis was performed in Pegasus ${ }^{\circledR}$ 4D GC $\times$ GC-TOFMS using Stabilwax-DA column ( $30 \mathrm{~m}, 0.25 \mathrm{~mm}$ ID, $25 \mu \mathrm{m}$ ) and helium as a carrier gas. The temperature of the injector was set at $250^{\circ} \mathrm{C}$; the column oven temperature was programmed from $35^{\circ} \mathrm{C}$ (held for $2 \mathrm{~min}$ ) to $240{ }^{\circ} \mathrm{C}$ at a ramp-up rate of $10^{\circ} \mathrm{C} / \mathrm{min}$ and held for $2 \mathrm{~min}$. The column flow rate was $1 \mathrm{ml} / \mathrm{min}$. Fatty acids were identified by comparison of the mass spectra with those in National Institute of Standards and Technology (NIST) libraries by mass fragmentation.

\section{Quantitative real time PCR ( $q P C R$ )}

Total RNA was isolated and purified from approximately $100 \mathrm{mg}$ frozen Gastrocnemius muscle using QIAzol lysis reagent (QIAGEN Sciences, USA) and RNA clean and Concentrator-25 (Inqaba Biotech, SA). Double stranded cDNA was synthesized from approximately $3 \mu \mathrm{g}$ of total RNA using Superscript Reverse Transcriptase III (Invitrogen, USA). Quantitative real time PCR were set up using Sensi Mix SYBER No-ROX one-step kit (Bioline, UK) and were cycled according to the Sensi Mix kit instructions in Rotor Gene-3000 (QIAGEN Sciences, USA) qPCR machine. In brief, RNA concentrations were estimated by measuring absorbance at $260 \mathrm{~nm}$, and purity was assessed by $260 \mathrm{~nm} / 280 \mathrm{~nm}$ absorbance ratio. Total RNA was added to the following oligo dT, random hexamer and dNTP and denatured at $65^{\circ} \mathrm{C}$ for $5 \mathrm{~min}$, incubated on ice and reverse transcribed by adding $0.1 \mathrm{M}$ DTT, Superscript Reverse Transcriptase III and $5 \times$ First strand buffer $(200$ $\mathrm{mM} \mathrm{NaCl}, 50 \mathrm{mM}$ Tris- $\mathrm{HCl}, 25 \mathrm{mM} \mathrm{MgSO}_{4}$ and $0.05 \%$ gelatine) followed by incubated at $25{ }^{\circ} \mathrm{C}$ for $5 \mathrm{~min}$ and $55^{\circ} \mathrm{C}$ for $60 \mathrm{~min}$. The reaction was inactivated by heat at $70{ }^{\circ} \mathrm{C}$ for $15 \mathrm{~min}$. Real time PCR was performed in triplicate using Rotor Gene-3000 Thermo cycler PCR machine, Sensi Mix SYBER green PCR reagent and primers (Integrated DNA Technologies, US) were used to amplify the region of Cpt-1 and Acc-1. The primers are, Cpt-1 forward 5' CGG TTC AAG AAT GGC ATC ATC 3'; Cpt-1 reverse 5' TCA CAC CCA CCA CCA CGA T 3' and Acc-1 forward 5' TAC AAC GCA GGC ATC AGA AG 3'; Acc-1 reverse 5' TGT GCT GCA GGA AGA TTG AC 3'. Amplification was occurred in a three-step cycle: denaturation at $95^{\circ} \mathrm{C}$ for $5 \mathrm{~s}$, annealing at $62{ }^{\circ} \mathrm{C}$ for $10 \mathrm{~s}$ and extension at $72{ }^{\circ} \mathrm{C}$ for $15 \mathrm{~s}$. Relative mRNA expression were normalized to Actin and GAPDH reference genes (Actin forward primer 3' GAC GAG GCC CAG AGC AAG AGA 5'; reverse primer 3' GGG TGT TGA AGG TCT CAA ACA 5'; GAPDH forward primer 3' GAA CAT CAT CCC TGC ATC C 5' reverse primer 3' CCT GCT TCA CCA CCT TCT T 5'). Expression ratio was calculated according to relative standard method.

\section{Statistical analysis}

Results are presented as means \pm SD. Statistical analysis was performed by one-way ANOVA followed Tukey's posthoc test. All statistical analyses were performed using GraphPad InStat 3 software. 


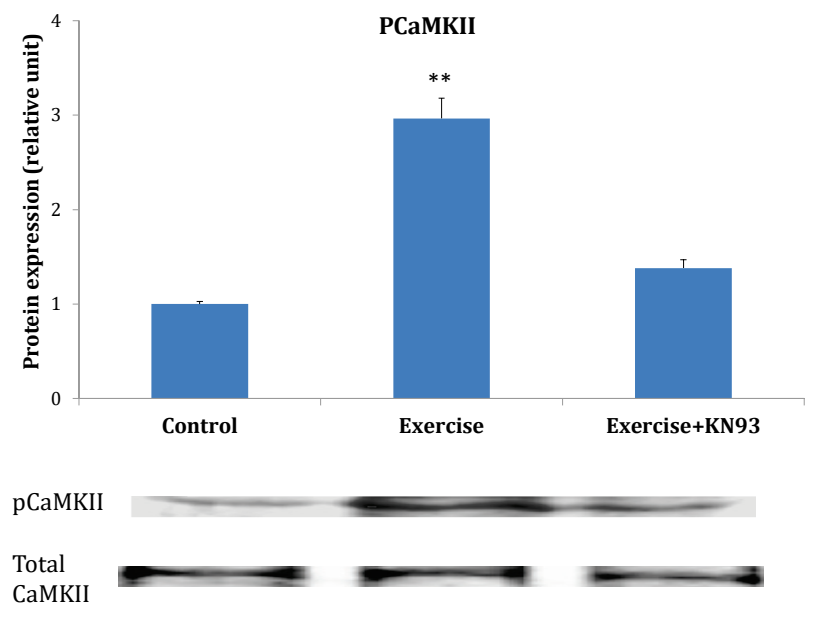

Fig. 2. Phosphorylation of CaMKII in response to exercise in rat skeletal muscle. The graph showed the protein expression of pCaMKII relative to total CaMKII and Western blot of pCaMKII and total CaMKII. The protein size is $36 \mathrm{kDa}$. ${ }^{*} * \mathrm{P}<0.01$ exercise + KN93 vs. exercise.

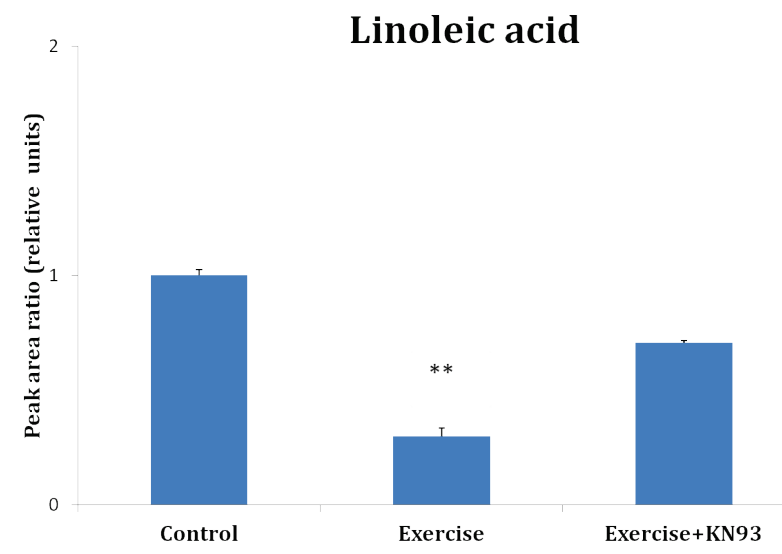

Fig. 3. Effects of CaMKII activation on linoleic acid levels in rat skeletal muscle. Gastrocnemius muscles were isolated from rats $6 \mathrm{~h}$ post exercise. It showed the fold changes in control, exercise, and exercise + KN93 groups. ${ }^{* *} \mathrm{P}<0.01$ exercise $+\mathrm{KN} 93$ vs. exercise.

\section{Arachidonic acid}

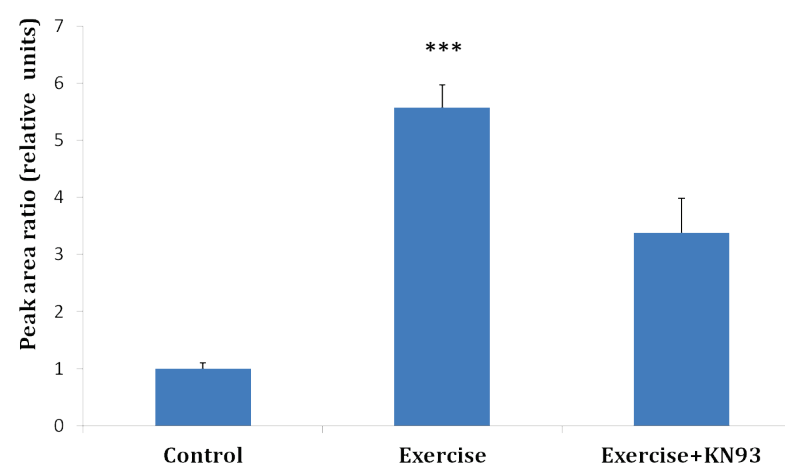

Fig. 4. Effects of CaMKII activation on arachidonic acid levels in rat skeletal muscle. Gastrocnemius muscles were isolated from rats $6 \mathrm{~h}$ post exercise. It shows the fold changes of control, exercise, and exercise+KN93 groups. $* * * \mathrm{P}<0.001$ exercise + KN93 vs. exercise.

\section{Results}

Exercise increased phosphorylation of CaMKII in rat skeletal muscle

In order to confirm that exercise phosphorylated CaMKII at Thr286, we assessed it together with total CaMKII expression using Western blotting. Figure 2 showed that phospho CaMKII protein expression of the exercise group was $\sim 2.9$ fold increase compared with the control group. Administration of KN93 prior to exercise prevented exercise-induced increase of CaMKII activation. However, expression levels of CaMKII of the exercise + KN93 group was reduced to levels relatively similar to those observed in the control group. Unlike phospho CaMKII, expression of total CaMKII did not change in response to exercise. This result confirms exercise-induced CaMKII activation in rat skeletal muscle.

CaMKII activation by exercise decreased linoleic acid levels in rat skeletal muscle

Linoleic acid is an omega 6 polyunsaturated fatty acid and is a precursor of AA. The diet provided for the rats contained $10 \%$ fat as source of LA and rats were not fed any animal-based foods. As shown in Figure 3, levels of LA in the exercise group showed $\sim 3.4$ fold decrease compared with the control group. However, LA levels of the exercise + KN93 group were similar to the levels of the control group. The results show that exercise-induced CaMKII activation increased oxidation of LA to their metabolites.

CaMKII activation by exercise increased arachidonic acid and 11,14-eicosadienoic acid levels in rat skeletal muscle

The levels of AA were assessed by using GC-MS. As shown in Figure 4, the AA levels of the exercise group showed $\sim 5.5$ fold increase compared with the non-exercise group. Inhibition of CaMKII using KN93 prior to exercise significantly reduced exerciseinduced increase of AA. The results show that CaMKII was involved in arachidonic acid biosynthesis.

Moreover, 11,14-eicosadienoic acid (ED) was assessed as an intermediate that is involved in the synthesis of AA from LA. As shown in Figure 5, ED levels of the exercise group showed $\sim 3.2$ fold increase compared with the control group. Administration of KN93 before exercise showed a significant decrease compared with the exercise group. The exercise + KN93 group's ED levels were similar to those of the control group and not statistically different from each other. The results indicate that exercise-induced CaMKII activation increased ED levels. 


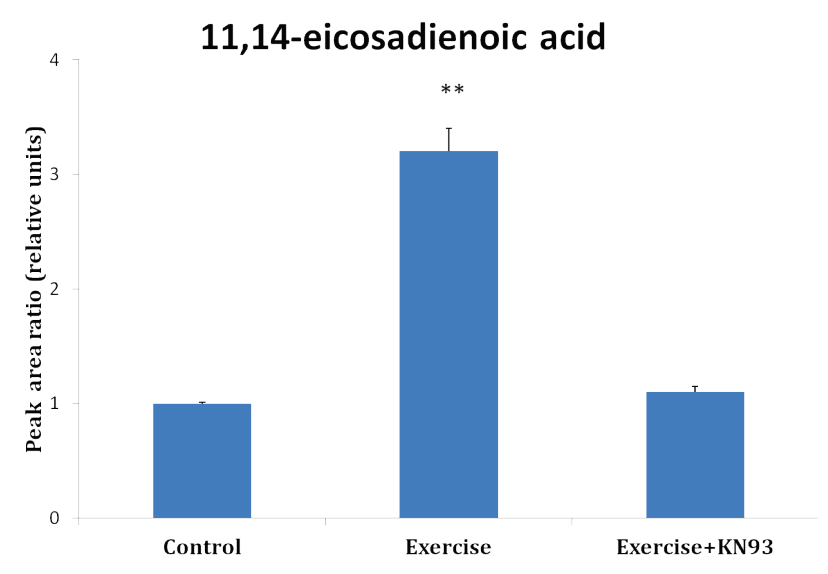

Fig. 5. Effects of CaMKII activation on 11,14-eicosadienoic acid levels in rat skeletal muscle. Gastrocnemius muscles were isolated from rats $6 \mathrm{~h}$ post exercise. It shows the fold changes of control, exercise, and exercise+KN93 groups. ${ }^{* *} \mathrm{P}<0.01$ control vs. exercise, $* * \mathrm{P}<0.01$ exercise $+\mathrm{KN} 93$ vs. exercise.

CaMKII activation by exercise increased CPT-1 gene expression in rat skeletal muscle

CPT-1 is an enzyme that encodes gene responsible for lipid oxidation. Cpt-1 gene expression of the exercise group showed $\sim 7.8$ fold increase compared with the control group. Cpt-1 gene expression of the exercise + KN93 group showed significant decrease compared with the exercise group. Cpt-1 gene expression of the exercise + KN93 was similar to the control group (Fig. 6). The results show that CaMKII activation increased Cpt-1 gene expression in rat skeletal muscle.

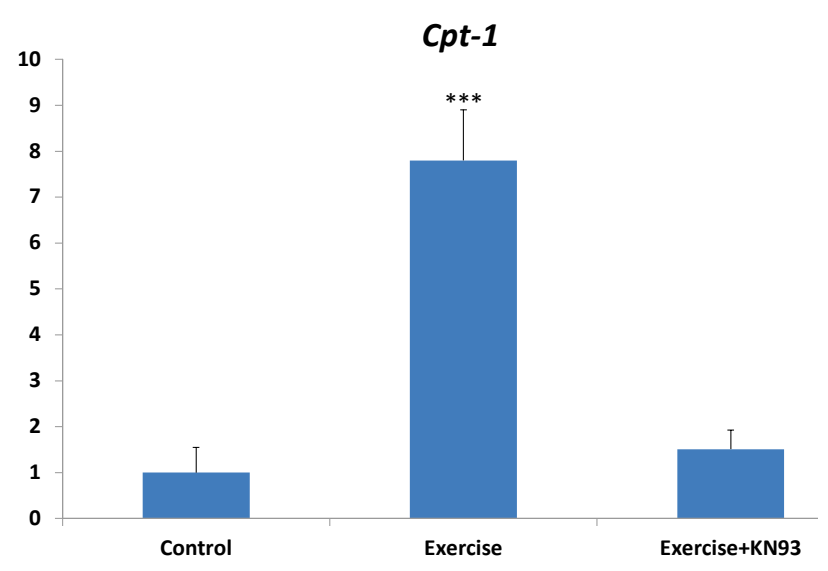

Fig. 6. Effects of CaMKII activation on Cpt-1 gene expression in rat skeletal muscle. Gastrocnemius muscles were extracted from the control, exercise, and exercise $+\mathrm{KN} 93$ groups $6 \mathrm{~h}$ post exercise. Cpt-1 gene expression of the exercise group showed $\sim 7.8$ fold increase compared with the control group, whereas the exercise + KN93 group showed $\sim 5.5$ fold decrease compared with the exercise group. $* * * \mathrm{P}<0.001$ control vs. exercise, $* * * \mathrm{P}<0.001$ exercise + KN93 vs. exercise.
CaMKII activation by exercise decreased ACC-1 gene expression in rat skeletal muscle

ACC-1 is an enzyme that encodes genes responsible for lipid biosynthesis. Acc-1 gene expression was analyzed by using qPCR. As shown in Figure 7, Acc-1 gene expression of the exercise group showed $\sim 1.9$ fold decrease compared with the control group and the exercise + KN93 group showed significant increase compared with the exercise group. These results showed that exercise-induced CaMKII activation decreased Acc-1 gene expression. These results are not surprising since CPT-1 and ACC-1 work antagonistically.

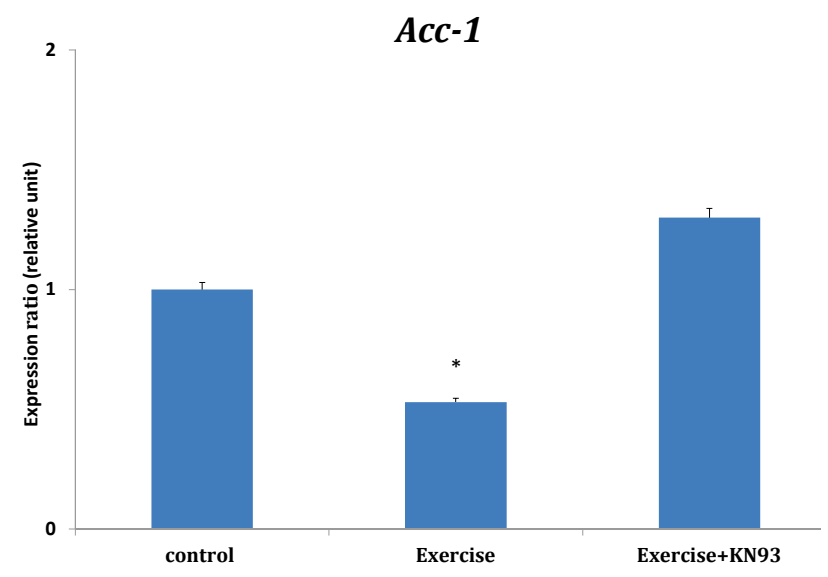

Fig. 7. Effects of CaMKII activation on $A c c-1$ gene expression in rat skeletal muscle. Gastrocnemius muscles were extracted from the control, exercise, and exercise $+\mathrm{KN} 93$ groups $6 \mathrm{~h}$ post exercise. Acc-1 gene expression of the exercise group showed $\sim 1.9$ fold decrease compared with the control group, whereas the exercise + KN93 group shows significant increase compared with the exercise group. * $\mathrm{P}<0.05$ control vs. exercise, $* \mathrm{P}<0.05$ exercise + KN93 vs. exercise.

\section{Discussion}

$\mathrm{KN}-93$ is a methoxybenzene sulfonyl derivative that competitively inhibits calmodulin binding to $\mathrm{CaM}$ kinase (Anderson et al. 1998). The effects of KN93 are mediated through CaMKII inhibition rather than through inhibiting any other enzyme activated by $\mathrm{Ca}^{2+} /$ calmodulin (Si and Collins 2008). The data presented in this study showed increased levels of AA in response to CaMKII activation. AA increase has been shown to alleviate the features related to type 2 diabetes (Borkman et al. 1993). Furthermore, it was observed that CaMKII activation by exercise reduced the level of LA. This indicates that exercise-induced CaMKII activation can increase synthesis of AA from LA and this could be as a result of series of desaturation and elongation steps. Moreover, it 
was also found that CaMKII activation by exercise increased the level of $\mathrm{ED}$, which is an intermediate involved in biosynthesis of AA. Therefore, exerciseinduced CaMKII activation could be beneficial to reduce symptoms of type 2 diabetes, such as insulin resistance through modulation of these fatty acids.

The activation of transcription factors by more than one signal transduction pathway or mechanism by exercise induced gene regulation in the skeletal muscle has been reported (Wackerhage et al. 2002). However, our study indicated that CaMKII activation by exercise regulated lipid metabolism genes in rat skeletal muscle. Studies have shown that exercise promotes lipid loss by increasing energy expenditure, lipid oxidation and increases the ability of skeletal muscle to use lipids (De Glisezinski et al. 2003, Goodpaster et al. 2003, Moro et al. 2005). The exact mechanism through which exercise improves lipid metabolism is not fully understood. In this study, we assessed CPT-1 and ACC-1 expression, which are responsible for lipid oxidation and synthesis. CPT-1 catalyzes the first step of mitochondrial long chain fatty acid oxidation and inhibited by malonyl CoA in skeletal muscle (McGarry et al. 1983) and malonyl CoA synthesized by ACC-1 (Hardie 1989, Awan and Saggerson 1993, Saha et al. 1995).

Exercise reduces level of malonyl $\mathrm{CoA}$ in skeletal muscle, which may be due to decreased activity of ACC (Winder and Hardie 1996). Therefore, reduction of malyonyl CoA by ACC-1 can prevent inhibition of CPT-1. Cpt-1 gene expression of exercise group showed $\sim 7.8$ fold increase compared to control group whereas exercise + KN93 did not show any significant change compared to control group. These results showed that
CaMKII activation increased CPT-1 expression in rat skeletal muscle. In addition, ACC-1 expression of exercise group showed significant decrease compared to control group. Administration of KN93 blocked the exercise-induced decrease of ACC-1 expression. This indicates that exercise-induced CaMKII activation regulates genes involved in lipid oxidation and synthesis in rat skeletal muscle. The effect of CaMKII activation in the regulation of ACC-1 and CPT-1 may influence the proportion of oxidized intramuscular fatty acids as an energy source. Therefore, exercise-induced CaMKII activation can improve lipid metabolism and alleviate symptoms of obesity and type 2 diabetes.

\section{Conclusion}

This study demonstrated that exercise-induced CaMKII activation increased the synthesis of AA from LA and regulated the genes that are responsible for lipid metabolism. It further explains why exercise has always been advocated as a means to alleviate many diseases. These results suggest that CaMKII could be an avenue for the design of effective therapeutic modalities that can be used in the treatment or management of type 2 diabetes and obesity.

\section{Conflict of Interest}

There is no conflict of interest.

\section{Acknowledgements}

Authors wish to acknowledge the National Research Foundation of South Africa for providing funding to Prof. Emmanuel Mukwevho, Grants no.: 76194 and 88062.

\section{References}

ANDERSON ME, BRAUN AP, WU Y, LU T, SCHULMAN H, SUNG RJ: KN-93, an inhibitor of multifunctional $\mathrm{Ca}++/$ calmodulin-dependent protein kinase, decreases early after depolarizations in rabbit heart. J Pharmacol Exp Ther 287: 996-1006, 1998.

AWAN MM, SAGGERSON ED: Malonyl-CoA metabolism in cardiac myocytes and its relevance to the control of fatty acid oxidation. Biochem J 295: 61-66, 1993.

BORKMAN M, STORLIEN LH, PAN DA, JENKINS AB, CHISHOLM DJ, CAMPBELL LV: The relation between insulin sensitivity and the fatty-acid composition of skeletal muscle phospholipids. $N$ Engl J Med 328: 238-244, 1980.

BRUCE CR, THRUSH AB, MERTZ VA, BEZAIRE V, CHABOWSKI A, HEIGENHAUSER GJF, DYCK DJ: Endurance training in obese humans improves glucose tolerance and mitochondrial fatty acid oxidation and alters muscle lipid content. Am J Physiol Endocrinol Metab 291: E99, 2006.

CHIN ER: Role of CAMKII in skeletal muscle plasticity. J Appl Physiol 99: 414-423, 2005. 
DE GLISEZINSKI I, MORO C, PILLARD F, MARION-LATARD F, HARANT I, MESTE M, BERLAN M, CRAMPES F, RIVIÈRE D: Aerobic training improves exercise-induced lipolysis in SCAT and lipid utilization in overweight men. Am J Physiol 285: 984-999, 2003.

DEAN D, DAUGAARD JR, YOUNG ME, SAHA A, VAVVAS D, ASP S, KIENS B, KIM KH, WITTERS L, RICHTER EA, RUDERMAN N: Exercise diminishes the activity of acetyl-CoA carboxylase in human muscle. Diabetes 49: 1295-1300, 2000.

FOLCH J, LEES M, STANELY GM: A simple method for the isolation and purification of total lipids from animal tissues. J Biol 226: 497-509, 1957.

GAO Z, ZHANG X, ZUBERI A, HWANG D, QUON MJ, LEFEVRE M, YE J: Inhibition of insulin sensitivity by free fatty acids requires activation of multiple serine kinases in 3T3-L1 adipocytes. Mol Endocrinol 18: 2024-2034, 2004.

GOODPASTER BH, KATSIARAS A, KELLEY DE: Enhanced fat oxidation through physical activity is associated with improvements in insulin sensitivity in obesity. Diabetes 52: 2191-2197, 2003.

GREENBERG AS, COLEMAN RA, KRAEMER FB: The role of lipid droplets in metabolic disease in rodents and humans. J Clin Invest 121: 2102-2110, 2011.

HARDIE DG: Regulation of fatty acid synthesis via phosphorylation of acetyl-CoA carboxylase. Prog Lipid Res $\mathbf{2 8}$ : 117-146, 1989.

HARDIE DG, PAN DA: Regulation of fatty acid synthesis and oxidation by the AMP-activated protein kinase. Biochem Soc Trans 30: 1064-1070, 2002.

HENSRUD DD: Dietary treatment and long-term weight loss and maintenance in type 2 diabetes. Obes Res 9: S348-S353, 2001.

HOLLOSZY JO: Adaptations of skeletal muscle mitochondria to endurance exercise: a personal perspective. Exerc Sport Sci Rev 32: 41-43, 2004.

HOLLOSZY JO, BOOTH FW: Biochemical adaptation to endurance exercise in muscle. Ann Rev Physiol 38: 273-291, 1976.

ICHIHARA K, SHIBAHARA A, YAMAMOTO K, NAKAYAMA T: An improved method for rapid analysis of fatty acids of glycerolipids. Lipids 31: 535-539, 1996.

KINFE HH, BELAY YH, JOSEPH JS, MUKWEVHO E: Evaluation of the influence of thiosemicarbazone-triazole hybrids on genes implicated in lipid oxidation and accumulation as potential anti-obesity agents. Bioorg Med Chem Lett 23: 5275-5278, 2013.

KNOWLER WC, BARRETT-CONNOR E, FOWLER SE, HAMMAN RF, LACHIN JM, WALKER EA, NATHAN DM: Reduction in the incidence of type 2 diabetes with lifestyle intervention or metformin. $N$ Engl J Med 346: 393-403, 2002.

KOVES TR, LI P, AN J, AKIMOTO T, SLENTZ D, ILKAYEVA O, DOHM GL, YAN Z, NEWGARD CB, MUOIO DM: Peroxisome proliferator-activated receptor-gamma co-activator 1alpha-mediated metabolic remodeling of skeletal myocytes mimics exercise training and reverses lipid-induced mitochondrial inefficiency. $J$ Biol Chem 280: 33588-33598, 2005.

MCAULEY KA, WILLIAMS SM, MANN JI, GOULDING A, CHISHOLM A, WILSON N, STORY G, MCLAY RT, HARPER MJ, JONES IE: Intensive lifestyle changes are necessary to improve insulin sensitivity: a randomized controlled trial. Diabetes Care 25: 445-452, 2002.

MCGARRY JD, MILLS SE, LONG CS, FOSTER DW: Observations on the affinity for carnitine, and M-CoA sensitivity, of carnitinepalmitoyltransferase $I$ in animal and human tissues: demonstration of the presence of malonyl-CoA in non hepatictissues of the rat. Biochem $J$ 214: 21-28, 1983.

MEIRER K, STEINHILBER D, PROSCHAK E: Inhibitors of the arachidonic acid cascade: interfering with multiple pathways. Basic Clin Pharmacol Toxicol 114: 83-91, 2014.

MORO C, PILLARD F, DE GLISEZINSKI I, HARANT I, RIVIÈRE D, STICH V, LAFONTAN M, CRAMPES F, BERLAN M: Training enhances ANP lipid-mobilizing action in adipose tissue of overweight men. Med Sci Sports Exerc 7: 1126-1132, 2005.

MUKWEVHO E, JOSEPH JS: Calmodulin dependent protein kinase II activation by exercise regulates saturated and unsaturated fatty acids and improves some metabolic syndrome markers. Life Sci 111: 53-61, 2014. 
MUKWEVHO E, KOHN TA, LANG D, NYATIA E, SMITH J, OJUKA EO: Caffeine induces hyperacetylation of histones at the MEF2 site on the Glut4 promoter and increases MEF2A binding to the site via a CaMKdependent mechanism. Am J Physiol Endocrinol Metab 294: E582-E588, 2008.

OJUKA EO, JONES TE, HAN DH, CHEN M, HOLLOSZY JO: Raising Ca2+ in L6 myotubes mimics effects of exercise on mitochondrial biogenesis in muscle. FASEB J 17: 675-681, 2003.

OLSON DP, PULINILKUNNIL T, CLINE GW, SHULMAN GI, LOWELL BB: Gene knockout of ACC2 has little effect on body weight, fat mass, or food intake. Proc Natl Acad Sci USA 107: 7598-7603, 2010.

O'NEILL HM, LALLY JS, GALIC S, PULINILKUNNIL T, FORD RJ, DYCK JR, VAN DENDEREN BJ, KEMP BE, STEINBERG GR: Skeletal muscle ACC2 S212 phosphorylation is not required for the control of fatty acid oxidation during exercise. Physiol Rep 3: e12444, 2015.

PAYNE ME, FONG YL, ONO T, COLBRAN RJ, KEMP BE, SODERLING TR, MEANS AR: Calcium/calmodulindependent protein kinase II. Characterization of distinct calmodulin binding and inhibitory domains. $J$ Biol Chem 263: 7190-7195, 1988.

PHINNEY SD: Arachidonic acid maldistribution in obesity. Lipids 31: S271-S274, 1996.

REN JM, SEMENKOVIK CF, GAO EA: Exercise induce rapid increase in GLUT 4 expression, glucose transport capacity and insulin stimulated glycogen storage in muscle. J Biol Chem 269: 14396-14401, 1994.

RETT BS, WHELAN J: Increasing dietary linoleic acid does not increase tissue arachidonic acid content in adults consuming Western-type diets: a systematic review. Nutr Metab 8: 36, 2011.

SAHA AK, KUROWSKI TG, RUDERMAN N: A malonylCoA fuel sensing mechanism in muscle: effects of insulin, glucose, and denervation. Am J Physiol Endocrinol Metab 269: E283-E289, 1995.

SALEM N JR, PAWLOSKY R, WEGHER B, HIBBELN J: In vivo conversion of linoleic acid to arachidonic acid in human adults. Prostaglandins Leukot Essent Fatty Acids 60: 407-410, 1999.

SI J, COLLINS SJ: Activated $\mathrm{Ca}^{2+} /$ calmodulin-dependent protein kinase IIgamma is a critical regulator of myeloid leukemia cell proliferation. Cancer Res 68: 3733-3742, 2008.

SMITH GI, ATHERTON P, REEDS DN, MOHAMMED BS, RANKIN D, RENNIE MJ, MITTENDORFER B: Omega-3 polyunsaturated fatty acids augment the muscle protein anabolic response to hyperinsulinaemiahyperaminoacidaemia in healthy young and middle-aged men and women. Clin Sci (Lond) 121: 267-278, 2011.

SMITH JA, COLLINS M, GROBLER LA, MAGEE CJ, OJUKA EO: Exercise and CaMK activation both increase the binding of MEF2A to the GLUT4 promoter in skeletal muscle in vivo. Am J Physiol Endocrinol Metab 292: E413-E420, 2007.

TERADA S, YOKOZEKI T, KAWANAKA K, OGAWA K, HIGUCHI M, EZAKI O, TABATA I: Effects of highintensity swimming training on GLUT-4 and glucose transport activity in rat skeletal muscle. J Appl Physiol 90: 2019-2024, 2001.

TIAN J, JI H, OKU H, ZHOU J: Effects of dietary arachidonic acid (ARA) on lipid metabolism and health status of juvenile grass carp, Ctenopharyngodon idellus. Aquaculture 430: 57-65, 2014.

TONG L: Acetyl-coenzyme A carboxylase: crucial metabolic enzyme and attractive target for drug discovery. Cell Mol Life Sci 62: 1784-1803, 2005.

WACKERHAGE H, WOODS NM: Exercise-induced signal transduction and gene regulation in skeletal muscle. J Sports Sci Med 1: 103-114, 2002.

WICKS SE, VANDANMAGSAR B, HAYNIE KR, FULLER SE, WARFEL JD, STEPHENS JM, WANG M, HAN X, ZHANG J, NOLAND RC, MYNATT RL: Impaired mitochondrial fat oxidation induces adaptive remodeling of muscle metabolism. Proc Natl Acad Sci USA 112: E3300-E3309, 2015.

WINDER WW, HARDIE DG: Inactivation of acetyl-CoA carboxylase and activation of AMP-activated protein kinase in muscle during exercise. Am J Physiol 270: E299-E304, 1996. 